\title{
A PHARMACOLOGICAL COMPARATIVE STUDY OF ARFORMOTEROL AND SALBUTAMOL NEBULIZATION IN THE MANAGEMENT OF PATIENTS SUFFERING FROM ACUTE NON-SEVERE BRONCHIAL ASTHMA
}

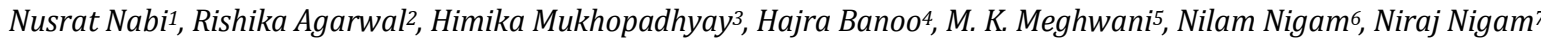 \\ ${ }^{1}$ Assistant Professor, Department of Pharmacology, Rama Medical College Hospital \& Research Centre, Kanpur. \\ 2Tutor, Department of Pharmacology, Rama Medical College Hospital \& Research Centre, Kanpur. \\ ${ }^{3}$ Tutor, Department of Pathology, Rama Medical College Hospital \& Research Centre, Kanpur. \\ 4 Professor and Head, Department of Physiology, Rama Medical College Hospital \& Research Centre, Kanpur. \\ 5 Professor, Department of T.B \& Chest Medicine, Rama Medical College Hospital \& Research Centre, Kanpur. \\ ${ }^{6}$ Professor and Head, Department of Pharmacology, Rama Medical College Hospital \& Research Centre, Kanpur. \\ 7MSc. Student, Department of Pharmacology, Rama Medical College Hospital \& Research Centre, Kanpur.
}

\section{ABSTRACT}

\section{BACKGROUND}

Arformoterol, is a long-acting beta-2 $(\beta-2)$ agonist which has a rapid onset and long duration of action. Not many studies in clinical setup have been done to analyse its role in acute attack of asthma.

Objectives- This study was planned to compare the efficacy and tolerability of monotherapy with arformoterol with salbutamol nebulization, in management of patients with acute non-severe asthma.

\section{MATERIALS AND METHODS}

A total of 60 patients of acute non-severe bronchial asthma were randomized into two groups in 1:1 ratio, to either receive three doses of salbutamol (5 mg) or arformoterol $(15 \mu \mathrm{g})$ nebulization, at 20 minutes intervals. The baseline characteristics of the subjects were measured at the baseline, which were comparable between the two groups and thus adequately matched. The primary outcome of the study was the measure of change in peak expiratory flow rate (PEFR); which was measured at the baseline and 5 minutes after each dose. All the emergent adverse events were also recorded.

Setting and Design- A prospective randomized parallel group, single blind, active control study; carried out in a tertiary care teaching hospital.

\section{RESULTS}

The results of this study reflected a significant increase in the mean PEFR in both the groups as compared with the baseline. However, the increase in the PEFR in two groups was comparable after the third dose, with no statistical significance. Both the treatments were well-tolerated with mild adverse effects in both the groups.

\section{CONCLUSION}

From the observations made in the study it is concluded that arformoterol is as effective and safe as salbutamol in the management of acute non-severe bronchial asthma.

\section{KEYWORDS}

Beta-2 ( $\beta$-2) Agonist, Bronchial Asthma, Bronchodilator, Peak Expiratory Flow Rate, Randomized Controlled Trial.

HOW TO CITE THIS ARTICLE: Nabi N, Agarwal R, Mukhopadhyay H, et al. A pharmacological comparative study of arformoterol and salbutamol nebulization in the management of patients suffering from acute non-severe bronchial asthma. J. Evolution Med. Dent. Sci. 2017;6(3):215-218, DOI: 10.14260/Jemds/2017/50

\section{BACKGROUND}

Asthma is a chronic inflammatory condition that involves hyper responsiveness of tracheobronchial smooth muscles, resulting in potential airway obstruction. The prevalence of asthma is increasing in most of the countries. About 300 million people worldwide have asthma and by 2025 it has been estimated that a further 100 million will be affected. ${ }^{1}$

Financial or Other, Competing Interest: None.

Submission 29-11-2016, Peer Review 30-12-2016,

Acceptance 02-01-2017, Published 09-01-2017.

Corresponding Author:

Dr. Nusrat Nabi,

Rama Medical College Hospital \& Research Centre

Staff Accommodation,

Mandhana, Kanpur-209217,

Uttar Pradesh, India.

E-mail: nusratnabinaikoo@gmail.com

DOI: $10.14260 /$ jemds $/ 2017 / 50$
Change in the epidemiology of asthma and its clinical spectrum is another global concern. ${ }^{2}$

The severity of symptoms and signs of asthma, along with the findings on functional lung assessment, are used to categorize asthma exacerbations as mild, moderate, severe, or life-threatening. ${ }^{3}$ The clinical diagnosis of asthma can be corroborated by changes in pulmonary function tests.

Beta-2 $(\beta-2)$ agonists are considered the first line drugs in the treatment of asthma. Short-acting $\beta-2$ agonists are the preferred drugs for the initial treatment of acute non-severe asthma because of their rapid onset of action. ${ }^{4}$ Long-acting $\beta$ 2 agonists such as salmeterol and formoterol are important controller medications in the maintenance therapy of chronic stable asthma and are generally used as an add-on drugs to inhaled corticosteroid. ${ }^{5}$ However their usefulness in the management of acute attacks of asthma has recently been recognized 6 and they are now approved for use as reliever medication in Europe. Formoterol is a unique bronchodilator having rapid onset and long duration of action. Formoterol 
provides an ideal rapid as well as long duration bronchodilatation thereby reducing the need for frequent administration. The onset of action of formoterol is similar to salbutamol (1-3 $\mathrm{min})^{7}$ with $80-90 \%$ of bronchodilatation occurring within 5-10 minutes of inhalation. ${ }^{8}$ The duration of action is up to 12 hours; $^{9}$ however, the duration of systemic effects with formoterol is found to be as short as that of salbutamol.10 The safety and tolerability of formoterol is well documented and is considered to be comparable to salbutamol. ${ }^{11}$ It is therefore an alternative to short-acting $\beta-2$ agonists in the management of acute asthma exacerbation. Arformoterol ([R, R] Formoterol) is a single isomer of formoterol and the only long-acting $\beta$ - 2 agonist available in India as a nebulizing solution; thus, we have used this drug considering the fact that the clinical pharmacology will be similar with formoterol.

Although safety and efficacy of drugs is established prior to marketing, it is important that comparison studies be undertaken by independent groups catering to specific population, to mirror the actual conditions in clinical practice and to assess the evaluating drug further in the postmarketing phase. Besides, there is also dearth of studyliterature demonstrating the role of arformoterol nebulization as a rescue medication, in patients with acute non-severe asthma. Hence, the objective of the present study is to compare the efficacy and safety of arformoterol with salbutamol nebulisation, in the management of patients with acute non-severe asthma.

\section{MATERIALS AND METHODS}

\section{Source of Data and Population}

The present study protocol was approval by the Institutional Ethics Committee (IRB) of Rama medical college hospital and research centre, Kanpur, India and the study was conducted in accordance with the International Conference on Harmonisation - Good Clinical Practice (ICH-GCP) guidelines. A written and signed informed consent was obtained from all the subjects enrolled in the study after the eligibility screening. The study was designed as a single-blind, randomized, controlled trial. The study was carried out on 60 patients of either sex, with acute non-severe asthma; attending the emergency or chest medicine out-patient clinic of a tertiary care hospital in Kanpur, over a period of 4 months, from July 2015 to October 2015. Patients with (a) age > 18 years; (b) British Thoracic Society definition of acute non-severe asthma ${ }^{12}$ and (c) ability to perform forced expiratory (PEFR) manoeuvre were included in the study. The exclusion criteria were the following: (a) patients presenting with acute severe/acute life-threatening/nearfatal asthma; (b) patients with a previous diagnosis of chronic obstructive pulmonary disease (COPD); (c) smokers (d) history of hypersensitivity to $\beta 2$ agonists; and (e) pregnant or lactating women.

\section{Demographic and Clinical Characteristics}

Age, sex, duration of asthma symptoms and controller medications used by the subjects were recorded. The pulse rate, respiratory rate, and $\mathrm{SpO}_{2}$ (Measured with Nidek Fingertip Pulse Oximeter 6500 model, India) were also recorded at the initial assessment. Anthropometric measurements like height and weight were recorded and BMI calculated. Peak expiratory flow rate (PEFR) was measured by 'Spiro Exel' (PC based, computerized software of Pulmonary Function Tests); at baseline and after each study drug dose.

\section{Study Design}

The patients were randomized in 1:1 ratio into two study groups, using computer generated random number list; receiving either salbutamol or arformoterol nebulization. Standard marketed brands of both the drugs were used and administered in a single blind manner, with medication identity not being revealed to the patients. In the salbutamol group, $5 \mathrm{mg}$ salbutamol respules were administered through oxygen driven $(6 \mathrm{~L} / \mathrm{min})$ nebulizer (Pulmo mist II nebuliser, Nidek Medical, India) at 20 minute intervals for 1 hour delivering a total of $15 \mathrm{mg}$. In the arformoterol group, a total $45 \mu \mathrm{g}$ of the drug was delivered as $15 \mu \mathrm{g}$ respules every 20 minutes for 1 hour, through the same nebulizer. Standard marketed brands of both the drugs were used and administered in a single blind manner. Allocation concealment was done by using the serially numbered, opaque, sealed envelope technique. The randomization process and the code breaking authority was given to a senior pharmacologist not interacting with the subjects. Systemic corticosteroids, to be given along with long acting $\beta$-agonists (LABA) ${ }^{13}$ were added only after the administration of third dose of the study drug, to eliminate the effects of other drugs on the treatment outcome.

\section{End-points and Safety Profile}

The primary end-point for the evaluation of efficacy of the study drugs was the change in PEFR. PEFR was measured 5 minutes after each dose of the study drug and the mean of the three PEFR measurements was recorded each time. The pulse rate, respiratory rate, and $\mathrm{SpO}_{2}$ were also recorded after each dose delivery. The patients were followed up for the next 6 hours following the third dose. Tolerability was assessed in terms of reported adverse experiences. All the adverse events, reported by the trial subjects were recorded in the structured case report form.

\section{Statistical Analysis}

Difference in mean PEFR between the two groups was analyzed by unpaired t-test. PEFR before and after each dose of the drug was also compared to determine whether there was significant improvement within the group by one-sample test. $\mathrm{P}<0.05$ was considered statistically significant.

\section{RESULTS}

A total of sixty patients were enrolled in the study; with 30 patients each in arformoterol and salbutamol group.

From Table 1 it is evident that the baseline characteristics of the two study groups were comparable and thus adequately matched.

Table 2 reflects the improvement in PEFR following the therapy with salbutamol and arformoterol nebulization. In both the groups, PEFR showed significant increase over the baseline values and the increase was evident after each dose of the drug. The increase in PEFR after the first and the second dose was significantly more with arformoterol than with salbutamol, but the increase in PEFR after third dose was similar in both the groups. 


\section{Safety Analysis}

As depicted in Table 3, both the drugs were well tolerated, no serious adverse events were encountered and all the adverse effects (AEs) noted were mild in either study group. All the AEs were classified as treatment emergent adverse events (TEAEs) across both study arms. The greatest number of subjects reported AEs in the system organ class of central nervous system disorders. In the salbutamol group, out of the 9 patients who experienced adverse effects; 2 complained of headache and 2 patients complained of muscular tremor; whereas, in the arformoterol group, out of the 7 patients with adverse effects; 2 patients complained of headache and 1 complained of tremor. No clinically significant safety findings were observed. Compliance was excellent in both the study groups and none of the patients discontinued the treatment.

\begin{tabular}{|c|c|c|}
\hline $\begin{array}{l}\text { Parameters } \\
\text { (Units) }\end{array}$ & $\begin{array}{c}\text { Salbutamol } \\
\text { Group } \\
(\mathrm{N}=30)\end{array}$ & $\begin{array}{l}\text { Arformoterol } \\
\text { Group } \\
(\mathrm{N}=30)\end{array}$ \\
\hline Age (years) & $30.20 \pm 5.78$ & $31.60 \pm 5.73$ \\
\hline Sex & & \\
\hline Male (\%) & $56.66(17)$ & $53.33(16)$ \\
\hline Female (\%) & $43.34(13)$ & $46.67(14)$ \\
\hline Weight (Kg) & $65.29 \pm 6.99$ & $67.7 \pm 6.18$ \\
\hline Height $(\mathrm{cm})$ & $170.32 \pm 4.94$ & $173.67 \pm 4.17$ \\
\hline $\begin{array}{l}\text { Respiratory rate } \\
\text { (breaths/min) }\end{array}$ & $18.50 \pm 0.92$ & $18.30 \pm 1.1$ \\
\hline Pulse rate (beats/min) & $95.30 \pm 2.41$ & $97.70 \pm 2.76$ \\
\hline $\mathrm{SpO}_{2}(\%)$ & $97.40 \pm 1.28$ & $97.10 \pm 1.18$ \\
\hline $\begin{array}{l}\text { Symptom duration } \\
\text { (years) }\end{array}$ & $5.80 \pm 3.15$ & $6.86 \pm 3.98$ \\
\hline \multicolumn{3}{|c|}{$\begin{array}{c}\text { Table 1. Demographic and Baseline Characteristics of the } \\
\text { Subjects in the Two Study Groups Comprising of } \\
\text { Salbutamol } 5 \text { mg (nebulization) and Arformoterol } 45 \mu \mathrm{g} \\
\text { (nebulization) }\end{array}$} \\
\hline
\end{tabular}

All parameters are arithmetic mean (standard deviation) SD, standard deviation; N, sample size

\begin{tabular}{|c|c|c|c|c|}
\hline $\begin{array}{c}\text { PEFR } \\
\text { (L/min) }\end{array}$ & $\begin{array}{l}\text { Salbutamol } \\
\text { Group } \\
(\mathrm{N}=\mathbf{3 0})\end{array}$ & $\begin{array}{c}\text { Arfor- } \\
\text { moterol } \\
\text { Group } \\
(\mathrm{N}=\mathbf{3 0})\end{array}$ & $\begin{array}{c}p- \\
\text { value }\end{array}$ & C.I \\
\hline Baseline & $235.0 \pm 3.0$ & $234.50 \pm 4.05$ & $>0.05$ & $\begin{array}{c}1.00- \\
2.00\end{array}$ \\
\hline $\begin{array}{c}\text { After first } \\
\text { dose } \\
\text { First } \\
\text { dose - } \\
\text { baseline }\end{array}$ & $\begin{array}{c}269.30 \pm 2.84 \\
34.50 \pm 1.62\end{array}$ & $\begin{array}{c}279.24 \pm 4.05 \\
44.30 \pm 1.89\end{array}$ & $<0.05$ & $\begin{array}{l}8.87- \\
10.72\end{array}$ \\
\hline $\begin{array}{l}\text { After second } \\
\text { dose } \\
\text { Second } \\
\text { dose- } \\
\text { baseline }\end{array}$ & $\begin{array}{c}293.10 \pm 4.93 \\
58.50 \pm 3.2\end{array}$ & $\begin{array}{l}304.40 \pm 6.1 \\
70.30 \pm 3.86\end{array}$ & $<0.05$ & $\begin{array}{c}0.941- \\
13.29\end{array}$ \\
\hline $\begin{array}{l}\text { After third } \\
\text { dose } \\
\text { Third dose - } \\
\text { baseline }\end{array}$ & $\begin{array}{c}314.90 \pm 5.17 \\
79.90 \pm 4.7\end{array}$ & $\begin{array}{c}320.20 \pm 4.57 \\
84.70 \pm 2.27\end{array}$ & $>0.05$ & $\begin{array}{c}0.973- \\
6.74\end{array}$ \\
\hline $\begin{array}{l}\mathrm{p}-\text { value } \\
\text { within } \\
\text { group }\end{array}$ & $<0.05$ & $<0.05$ & & \\
\hline \multicolumn{5}{|c|}{$\begin{array}{c}\text { Table 2. Descriptive Summary and Statistical Comparison of PEFR } \\
\text { in the Salbutamol } 5 \text { mg (nebulization) and Arformoterol } 45 \mu \mathrm{g} \\
\text { (nebulization) Study Groups }\end{array}$} \\
\hline
\end{tabular}

All parameters are arithmetic mean (standard deviation) SD, standard deviation; N, sample size; C.I, confidence interval; $\mathrm{p}>0.05=$ significant; $\mathrm{p}<0.05=$ not significant

\begin{tabular}{|c|c|c|}
\hline $\begin{array}{c}\text { Adverse } \\
\text { Events }\end{array}$ & $\begin{array}{c}\text { Salbutamol } \\
\text { Group } \\
(\mathbf{N}=\mathbf{3 0})\end{array}$ & $\begin{array}{c}\text { Arformoterol } \\
\text { Group } \\
(\mathbf{N}=\mathbf{3 0})\end{array}$ \\
\hline Headache & 2 & 2 \\
\hline Tremor & 2 & 1 \\
\hline Nausea/oral irritation & 3 & 2 \\
\hline Palpitation & 2 & 2 \\
\hline $\begin{array}{c}\text { Table 3. Adverse Event Profile of the Salbutamol 5 mg } \\
\text { (nebulization) and Arformoterol 45 } \\
\text { Mg (nebulization) } \\
\text { Study Groups }\end{array}$ \\
\hline
\end{tabular}

$\mathrm{N}$, sample size

\section{DISCUSSION}

Asthma is a disease which besides having a considerable economic burden has physical, emotional and social effects as well; leading to reduced quality of life of patients and their families. ${ }^{14}$ The goal of treatment of asthma is to improve patients' quality of life by providing rapid relief of symptoms and reducing the severity and number of recurrent episodes. Although short acting $\beta-2$ agonists are used in acute exacerbations of asthma; the usefulness of long acting $\beta$-2 agonists has recently been recognized in the management of acute attacks of asthma. Hence, the objective of our study was to compare arformoterol with salbutamol nebulization in the management of acute non severe asthma.

The results of our study reflect that arformoterol is as effective as a reliever medication, as salbutamol, in acute nonsevere asthma. Statistically significant improvement in PEFR as compared to the baseline was demonstrated in both the groups. Several studies have shown the efficacy of formoterol in acute non-severe asthma, acute severe asthma, exercise induced bronchospasm, childhood asthma, and COPD.15-19 Although few studies have shown clinically significant improvement in lung function (FEV1) with formoterol when compared with salbutamol, ${ }^{16}$ most studies have shown a comparable efficacy. ${ }^{15,17}$ Safety of formoterol is also well documented even at high doses in patients with asthma and COPD. ${ }^{11,20}$ Although it is a long-acting drug, systemic effects with formoterol are as short as salbutamol.10

Relatively, hydrophilic drugs such as salbutamol have rapid onset of action due to their ability to reach the $\beta 2$ receptor from the aqueous phase.21 Formoterol is a moderately lipophilic drug, about 300 times more than salbutamol.22 The aqueous portion rapidly activates the $\beta 2$ receptor, whereas the lipophilic portion is taken up into the cell membrane from which it diffuses slowly to stimulate $\beta 2$ receptor over a prolonged period. This accounts for rapid onset along with long duration of action of formoterol. ${ }^{23}$ In this study the increases in PEFR after the first and the second dose were significantly more with arformoterol than with salbutamol; proving that arformoterol has a rapid onset of action.

Both the drugs were well tolerated with no serious adverse events. Very few adverse events were documented which were mild and comparable between these the two drugs. Dryness of mouth was the most reported side effect of formoterol inhalation in one study. ${ }^{15}$ In our study, the greatest number of AEs were reported in the system organ class of central nervous system disorders, with headache and muscle tremors being the most commonly reported. In few studies, the impact of high-dose formoterol on heart rate, 
blood pressure, serum potassium, electrocardiogram changes, and arterial blood gas were assessed which showed identical changes comparable with salbutamol.16,20 However, in our study we only evaluated the adverse effects reported by the patients.

The main limitation of this study was its restriction to patients of acute non-severe asthma only. The efficacy and tolerability of arformoterol in severe asthma and acute exacerbation of COPD are yet to be explored. The objective assessment of adverse effects and laboratory abnormalities were not studied. No arrangement to assess the persistence of adverse events was done as the patients were not followed up after the discharge. Also, as with all single blinded trials, the possibility of bias in subjective assessment by the attending investigator was present in this study as well.

\section{CONCLUSION}

From the observations of the present study it can be concluded that arformoterol is comparable in terms of efficacy and safety to salbutamol. However, further studies are thus needed to establish the long-term safety of arformoterol in acute exacerbations of asthma and COPD with different levels of severity, especially in Indian population.

\section{Acknowledgments}

We would like to thank Dr. Nasir Nabi Naikoo, postgraduate trainee, department of pathology, for assistance in laboratory investigations; and Mrs. Chitra $\mathrm{R}$ Chauhan, statistician, department of community medicine, for assistance in data analysis.

\section{REFERENCES}

[1] Rees J. Asthma control in adults. BMJ 2006;332(7544):767-71.

[2] Aggarwal AN, Chaudhry K, Chhabra SK, et al. Prevalence and risk factors for bronchial asthma in Indian adults: a multicentre study. Indian J Chest Dis Allied Sci 2006;48(1):13-22.

[3] US department of health and human services, national institute of health, national heart, lung, and blood institute. Expert panel report 3: guidelines for the diagnosis and management of asthma 2008.

[4] Gopinath VP, Rao MS. Management of acute severe asthma. Medicine Update API 2010;20:784-5.

[5] Bateman ED, Hurd SS, Barnes PJ, et al. Global strategy for asthma management and prevention: GINA executive summary. Eur Respir J 2008;31(1):143-78.

[6] Hospenthal MA, Peters JI. Long-acting $\beta 2$-agonists in the management of asthma exacerbations. Curr Opin Pulm Med 2005;11(1):69-73.

[7] Wegener T, Hedenstrom H, Melander B. Rapid onset of action of inhaled formoterol in asthmatic patients. Chest 1992;102(2):535-8.

[8] Tattersfield AE. Clinical pharmacology of long acting beta-receptor agonists. Life Sci 1993;52(26):2161-9.
[9] Ringdal N, Derom E, Wahlin-Boll E, et al. Onset and duration of action of single doses of formoterol inhaled via turbuhaler. Respir Med 1998;92(8):1017-21.

[10] Rosenborg J, Bengtsson T, Larsson P, et al. Relative systemic dose potency and tolerability of inhaled formoterol and salbutamol in healthy subjects and asthmatics. Eur J Clin Pharmacol 2000;56(5):363-70.

[11] Malolepszy J, Nagy BG, Selroos 0, et al. Safety of formoterol turbuhaler at cumulative dose of 90 microg in patients with acute bronchial obstruction. Eur Respir J 2001;18(6):928-34.

[12] British thoracic society, scottish inter collegiate guidelines network. British guidelines on the management of asthma. Thorax 2008;63(Suppl 4):iv1121.

[13] Suissa S, Ernst P, Benayoun S, et al. Low-dose inhaled corticosteroids and the prevention of death from asthma. N Engl J Med 2000;343(5):332-6.

[14] Holgate ST, Price D, Valovirta E. Asthma out of control? A structured review of recent patient surveys. BMC Pulm Med 2006;6(Suppl 1):S2.

[15] Najafizadeh K, Pour SH, Ghadyanee $M$, et al. A randomised, double- blind, placebo-controlled study to evaluate the role of formoterol in the management of acute asthma. Emerg Med J 2007;24(5):317-21.

[16] Boonsawat W, Charoenratanakul S, Pothirat C, et al. Formoterol (oxis) turbuhaler as a rescue therapy compared with salbutamol pMDI plus spacer in patients with acute severe asthma. Respir Med 2003;97(9):1067-74.

[17] Bronsky EA, Yegen U, Yeh CM, et al. Formoterol provides long-lasting protection against exerciseinduced bronchospasm. Ann Allergy Asthma Immunol 2002;89(4):407-12.

[18] Whale CI, Sovani MP, Mortimer KJ, et al. Systemic and bronchodilator effects of inhaled rac-formoterol in subjects with chronic obstructive pulmonary disease: a dose-response study. $\mathrm{Br} \mathrm{J}$ Clin Pharmacol 2008;65(6):841-7.

[19] Singhania N, Dhamija R, Lodha R, et al. Salmeterol vs formoterol: a comparison of rapid bronchodilator effect in a randomised controlled trial. Indian Pediatr 2008;45(3):225-8.

[20] Maesen FP, Costongs R, Brombacher PJ, et al. The effect of maximal doses of formoterol and salbutamol from metered dose inhaler on pulse rate, ECG, and and serum potassium concentrations. Chest 1991;99(6):1367-73.

[21] Seberova E, Anderson A. Oxis (formoterol given by turbuhaler) showed as rapid an onset of action as salbutamol given by a pMDI. Respir Med 2000;94(6):607-11.

[22] Johnson M. Effects of beta2-agonists on resident and infiltrating inflammatory cells. J Allergy Clin Immunol 2002;110(6 Suppl):S282-90.

[23] Anderson GP. Formoterol: pharmacology, molecular basis of agonism, and mechanism of long duration of a highly potent and selective beta2 adrenoceptor agonist bronchodilator. Life Sci 1993;52(26):2145-60. 